\title{
镍 $N$-杂环卡宾配合物在均相催化偶联反应中的应用
}

\author{
顾绍金，倪 鹏，陈万芝 \\ 浙江大学化学系, 浙江杭州 310028
}

\begin{abstract}
摘要: 近十几年来, $N$-杂环卡宾的配位化学和金属有机化学发展迅速,已成为均相催化反应中研究最为广泛的配体之一. 在许多 过渡金属催化的有机合成反应中特别是偶联反应中, $N$-杂环卡宾与传统有机膦配体相比具有较高的反应性. 镍价格低廉, 在很 多反应中有望替代贵金属钯催化剂. 本文总结了镍 $N$-杂环卡宾化合物在催化交叉偶联反应和还原偶联反应中的最新应用进展. 关键词: 镍; $N$-杂环卡宾; 交叉偶联反应; 还原偶联; 均相催化

中图分类号: 0643 文献标识码: A

\section{$N$-Heterocyclic Carbenes: Versatile Reagents for Nickel-Catalyzed Coupling Reactions}

\author{
GU Shaojin, NI Peng, CHEN Wanzhi* \\ Department of Chemistry, Zhejiang University, Hangzhou 310028, Zhejiang, China
}

\begin{abstract}
The chemistry of $N$-heterocyclic carbenes (NHCs) has grown rapidly in the past decade. NHCs are now important ligands in homogeneous catalysis that show better catalytic activities than the typical phosphines in a number of transition metal catalyzed organic transformations, especially in $\mathrm{C}-\mathrm{C} /$ heteroatom bond formation reactions. $\mathrm{Ni}$ is a much cheaper metal and the most promising alternative to $\mathrm{Pd}$, and is receiving increasing attention. In this article we summarize new developments in the catalytic applications of nickel-NHC complexes in coupling reactions that include typical cross couplings of organic halides with various organometallic reagents and reductive coupling reactions.
\end{abstract}

Key words: nickel; $N$-heterocyclic carbene; cross-coupling reaction; reductive coupling; homogeneous catalysis

Since the isolation and characterization of the first free $\mathrm{N}$-heterocyclic carbene (NHC) by Arduengo and co-workers in 1991 [1], a wide range of structurally diverse NHCs and their metal complexes have been studied and used in catalysis. Their striking similarity to electron-rich organophosphines $\left(\mathrm{PR}_{3}\right)$, low toxicity, and excellent $\sigma$-donating properties make them the ligands of choice for transition metals. A number of monodentate, bidentate, and polydentate NHC complexes have found wide applications in pharmaceutical science, materials science, and organic synthesis. The most intensively studied catalytic processes to date are $\mathrm{C}-\mathrm{C}$ coupling reactions promoted by $\mathrm{NHC}$ complexes of palladium. Nickel, as a much cheaper metal and the most promising alternative to $\mathrm{Pd}$, is receiving increasing atten- tion. Some nickel complexes have been shown to be catalytically active for a wide range of reactions such as $\mathrm{Su}$ zuki-Miyaura [2-6], Kumada-Corriu couplings [7-12], Negishi cross-coupling reactions [13], Heck reactions [14-16], arylation of acyclic ketone [17], cycloaddition reactions [18-22], dimerization and polymerization of olefins [23-33], C-C bond activation of biphenylene [34], transfer hydrogenation of imines [35], and dehalogenation of aryl halides [36]. The synthesis and applications of Ni-NHC complexes have been previously summarized [37-39]. Here we focus on recent progress in the catalytic applications of $\mathrm{Ni}$ complexes of NHCs in homogenous coupling reactions.

\section{Cross-coupling reactions}

Received date: 11 May 2010.

*Corresponding author. Fax: +86-571-88273314; E-mail: chenwzz@zju.edu.cn

Foundation item: Supported by the National Natural Science Foundation of China (20872129, J0830413) and the Chinese Universities Scientific Fund (2009QNA3004).

English edition available online at ScienceDirect (http://www.sciencedirect.com/science/journal/18722067). 


\section{1 $\mathrm{C}-\mathrm{C}$ bond forming reactions}

\subsubsection{Kumada-Corriu reaction}

The most economical nickel-catalyzed $\mathrm{C}-\mathrm{C}$ bond formation reaction is undoubtedly the Kumada-Corriu reaction. Although Grignard reagents are air and moisture sensitive, the most commonly used organometallic reagents, including boronic acids, organozincs, and stannanes, are actually prepared from the corresponding organomagnesium compounds.
The first Ni-catalyzed Kumada-Corriu reaction was reported by Herrmann and co-workers [10], which allowed the coupling of aryl chlorides to proceed at room temperature using $3 \mathrm{~mol} \%$ of $\mathrm{Ni}$ (Scheme 1(a)). Soon after, they reported that $5 \mathrm{~mol} \%$ of complex 3 (Scheme 2) efficiently catalyzed the coupling of aryl Grignard reagents and aryl fluorides to yield biaryls in high yields [11]. A further investigation discovered that a better catalyst can be generated in situ from a 1:1 mixture of $\mathrm{Ni}(\mathrm{acac})_{2}$ and $\mathrm{IPr} \cdot \mathrm{HBF}_{4}(\mathrm{IPr}=$ 1,3-bis(2,6-diisopropylphenyl)imidazolin-2-ylidene) (2b), thus avoiding the use of the air-sensitive zero-valent $\mathrm{Ni}$ (a)<smiles>[R2]c1ccc(-c2cccc(-c3ccc([R])cc3[R])c2)cc1</smiles><smiles></smiles>

$\mathrm{X}=\mathrm{Cl}^{-}$, 1a, IMes $\cdot \mathrm{HCl}$ $\mathrm{X}=\mathrm{BF}_{4}^{-}, \mathbf{1 b}$, IMes $\cdot \mathrm{HBF}_{4}$ (b)

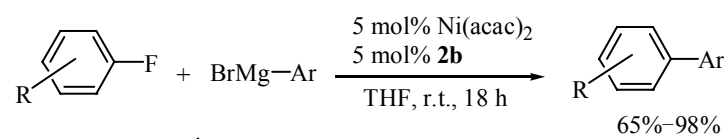

Scheme 1. Kumada-Corriu reaction of aryl chlorides and aryl fluorides.<smiles>[Al]C1C=CN([AlH2])C1NC1N([Al])C=CN1[AlH2]</smiles>

3

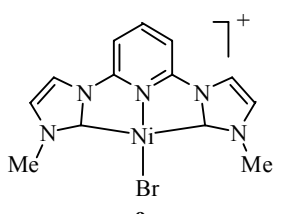
9

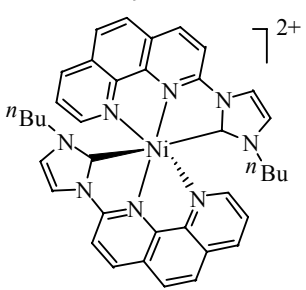

15

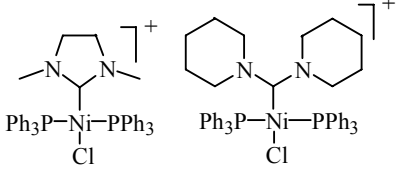

4

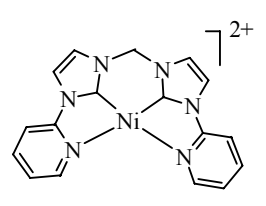

10

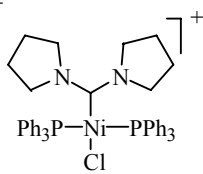

6

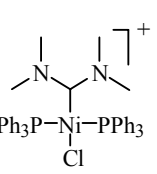

7

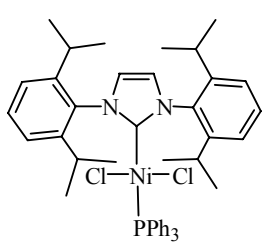

$8 \mathbf{a}$
$\mathrm{X}=\mathrm{Cl}^{-}$, 2a, $\mathrm{IPr} \cdot \mathrm{HCl}$

$\mathrm{X}=\mathrm{BF}_{4}^{-}, \mathbf{2} \mathbf{b}, \operatorname{IPr} \cdot \mathrm{HBF}_{4}$

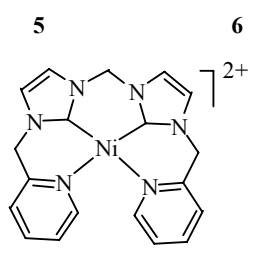

11

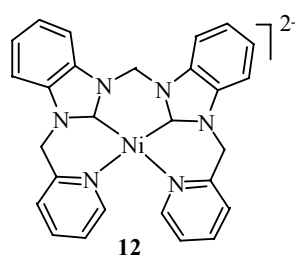

12

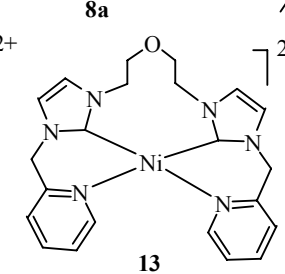

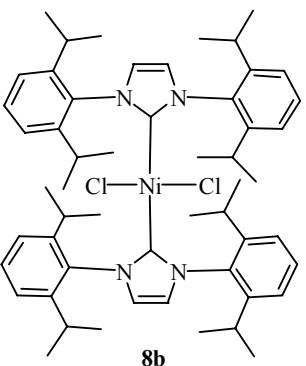

$8 \mathrm{~b}$

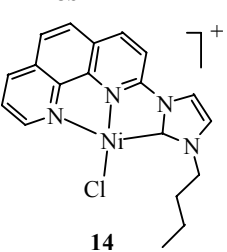<smiles>[R]N1C=CN2CC(Cl)=C3CN4C=CN([R])N4C3N(C(C)(C)C[3H])C12</smiles>

16a, $\mathrm{R}=\mathrm{Ph} ; \mathbf{1 6 b}$, mesityl

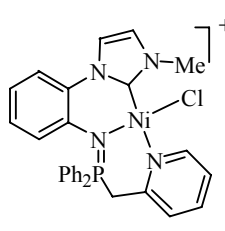

17

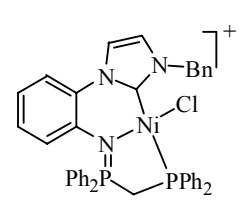

18

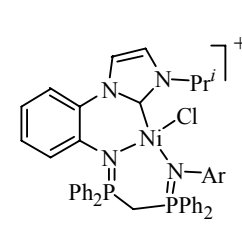

19

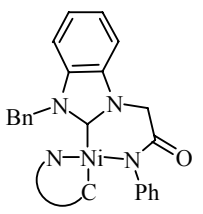

24

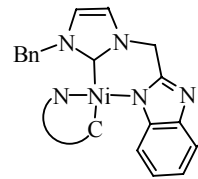

25

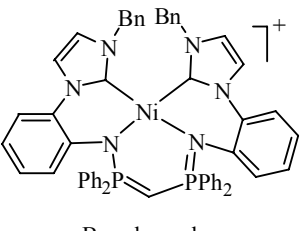

$\mathrm{Bn}=$ benzyl

20

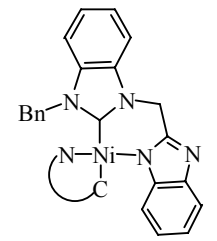

26

Scheme 2. Schematic representation of nickel complexes 3-26. 
complex 3. Using this system, both electron-rich and electron-poor aryl fluorides were successfully coupled with a variety of aryl Grignard reagents to generate the biaryls in good to excellent yields (Scheme 1(b)).

Since then, a number of well defined Ni-NHC systems have been studied for this transformation. Furstner and co-workers [40] extended the Kumada-Corriu coupling to aryl and heterarene halides using the single ligand Ni-NHC complexes 4-7 at ambient temperature (Scheme 2). These novel nickel-NHC complexes were active in the $\mathrm{Ku}$ mada-Corriu coupling of $p$-methoxyphenylmagnesium bromide with chloro- or bromobenzene as well as 2-chloropyridine in the presence $3 \mathrm{~mol} \%$ of the catalyst. The mixed $\mathrm{NHC} / \mathrm{PPh}_{3}$ complex 8a and bicarbene complex $\mathbf{8 b}$ were also applied to this reaction by using only 0.5 mol\% of the catalysts (Scheme 2) [41]. Complex 8a exhibited a higher activity than complex $\mathbf{8 b}$, which is possibly due to the stability provided by the bulky NHC ligand and lability of the triphenylphosphine ligand on the nickel.

The catalytic activity of nickelacycle 9 in the $\mathrm{Ku}$ mada-Corriu coupling reaction was evaluated by Inamoto et al. [3]. This complex turned out to be a good pre-catalyst in the reaction between both electron-rich and neutral aryl halides and $\mathrm{PhMgCl}, \mathrm{PhMgBr}$ or para- $\mathrm{MeOPhMgBr}$ affording good yields when a catalytic loading of $5 \mathrm{~mol} \%$ was used (Scheme 2). A decrease in the amount of the catalyst precursor led to moderate yields. It is to be noted that this system is suitable for the catalytic cleavage of $\mathrm{C}\left(s p^{2}\right)$-fluorine bonds although only a moderate yield was obtained with a longer reaction time.

A number of nickel(II) complexes of multidentate NHCs have been prepared, structurally characterized, and catalytic applications studied by our group (Scheme 2, 10-13). Such nickel complexes are highly active catalysts for the $\mathrm{Ku}$ mada-Corriu coupling of various aryl chlorides at room temperature in the presence of $2 \mathrm{~mol} \%$ catalyst loading [9]. This method also allowed the formation of biphenyls in high yields even when electron-rich aryl chlorides were used. The catalysts are economical, air-stable, and easily available. The high catalytic activities of these nickel complexes are probably because of the stabilization effect of the pyridine-functionalized bis(NHC) ligands on the catalytically active species by the formation of stable $\mathrm{Ni}-\mathrm{C}$ bonds and the hemi-lability of the pyridine group on the metal. Comparative studies showed that complex $\mathbf{1 0}$ was more active than 11-13.

We found that the unsymmetrical NNC pincer Ni-NHC complexes 14 and 15 were also highly active in the $\mathrm{Ku}$ mada-Corriu coupling reaction of aryl chlorides at room temperature at a catalyst loading of $1 \mathrm{~mol} \%$ [42]. The tetracoordinate complex 14 was much more active than the hexacoordinate nickel complex $\mathbf{1 5}$ for the coupling of various aryl chlorides with $p$-tolylmagnesium bromide. This is easily understood since the generation of catalytically active species from the hexacoordinate complex of 20 e configuration would be more difficult than from the tetracoordinate complex of 16 e configuration (Scheme 2). A further investigation led to the isolation of the unexpected pincer $\mathrm{CC}^{\prime} \mathrm{C}$ complexes $16 \mathbf{a}$ and $\mathbf{1 6 b}$, which were synthesized by the transmetalation and intramolecular chloronickelation of the triple bond of NHC-substituted alkynes [43]. The resulting nickel complexes exhibited high catalytic activity in the Kumada-Corriu reactions involving aryl and heteroaryl chlorides at room temperature in the presence of $0.5 \mathrm{~mol} \%$ of catalysts.

The use of nickel-NHC complexes 17-20 in the $\mathrm{Ku}$ mada-Corriu reaction was also recently studied by Zhang et al. [44]. Complexes 17-20 were active catalysts for Negishi and Kumada-Corriu coupling reactions with activated aryl chlorides and deactivated aryl chlorides substrates at room temperature (Scheme 2). They found that the CNN-chelate nickel complexes exhibited higher catalytic activities than 20 due to the restriction of incoming substrates on the available coordination sites.

Various arenesulfonates can also be used as coupling partners for cross-couplings with methyl, neopentyl, and benzyl Grignard reagents at ambient temperature using nickel-NHC catalysts generated in situ from $\mathrm{Ni}(\mathrm{acac})_{2}$ and imidazolium salts (Scheme 3) [45]. The reactions rapidly proceed to afford high yields with only 1.5 equivalent of methyl and neopentyl nucleophiles at room temperature.

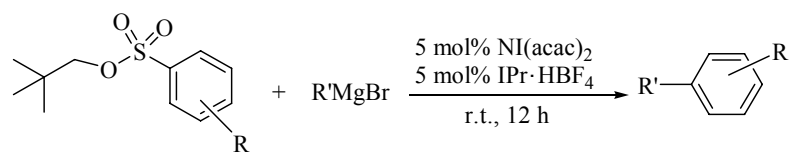

Scheme 3. Kumada-Corriu coupling reaction of arenesulfonates.

Huynh and co-workers [46] reported the synthesis and characterization of $\mathbf{2 1}$ and $\mathbf{2 2}$ bearing $N$-heterocyclic dicarbene ligands (Scheme 2). They concluded that complex 22 showed a higher activity with a wide range of aryl halides at ambient temperature and it outperformed complex 21. Although complex $\mathbf{2 2}$ is generally very active in the coupling of both activated and deactivated aryl bromides giving more than $70 \%$ yields, it only gave moderate yields for sterically bulky and deactivated substrates. Berding et al. [47] reported similar $\mathrm{Ni}(\mathrm{II})$ dihalide complexes for the $\mathrm{Ku}$ mada-Corriu coupling of 4-chloroanisole and 4-bromoanisole with phenylmagnesium chloride. Complexes 23-26 were catalytically active in the coupling of 4-chloroanisole with phenylmagnesium chloride at room temperature (Scheme 2) [48]. Nearly quantitative yields were obtained in less than 20 min when complexes 25 and $\mathbf{2 6}$ with benzimidazole-substituted ligands were used. Compared to the 
catalytic results obtained with the nickel catalysts of bis(NHC) ligands, the complexes with anionic $\mathrm{C}, \mathrm{N}$ ligands performed remarkably well. 4-Fluoroanisole can be coupled efficiently and nearly quantitatively within $150 \mathrm{~min}$ using 1 $\mathrm{mol} \%$ of $\mathbf{2 6}$. The high rate of the reaction was ascribed to the nickel/magnesium bimetallic cooperation mechanism.
As shown in Scheme 4, the mechanism implied that two anionic N-donor moieties must be replaced by two phenyl groups to yield a pendant anionic $\mathrm{N}$-donor group coordinated to the liberated $[\mathrm{MgCl}]^{+}$species (Scheme 4, B). These magnesium cations may then facilitate the formation of the transition state $\mathbf{C}$ in the oxidative addition of the aryl halide.

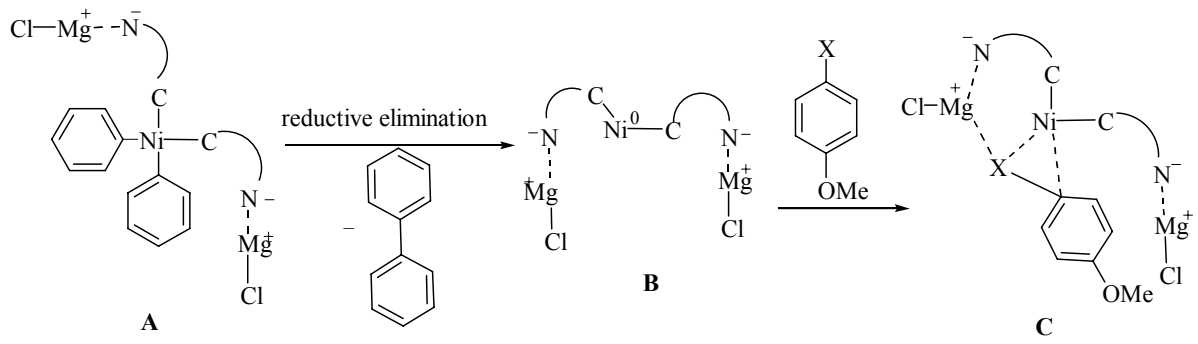

Scheme 4. Proposed mechanism for the activation of the pre-catalyst and the transition state for carbon-halide bond activation.

Nickel(I) complex 27 was shown to be an efficient catalyst in the catalytic Kumada-Corriu coupling reactions of aryl halides [49]. The novel T-shape three-coordinate nickel(I) chloride bearing the IPr ligand was selectively formed and isolated by the reactions of $\left[\mathrm{Ni}(\mathrm{IPr})_{2}\right](3)$ with aryl chlorides (Scheme 5). The selective formation of nickel(I) complex 27 from $\mathbf{3}$ and an aryl halide may allow the identification of the actual active catalyst in the $\mathrm{Ni}(\mathrm{I})-\mathrm{Ni}(\mathrm{III})$ cycle.

\subsubsection{Negishi reaction}

The coupling of organozinc, organoaluminum, or organozirconium derivatives (the so-called Negishi reaction) is a versatile cross-coupling reaction for $\mathrm{C}-\mathrm{C}$ bond formation. This reaction has enhanced functional group tolerance as compared to the Kumada-Corriu reaction. It is compatible with many functional groups including ketones, esters, amines, and nitriles, and there are a variety of routes for making these organometallic reagents. Therefore, the Negishi reaction is often chosen for the preparation of complex functional products.

Surprisingly, Ni-NHC-mediated Negishi coupling is rare. We have reported the first example of a Ni-NHC catalyzed coupling of organozinc reagents with aryl halides [13]. The mononuclear complexes (10-13) and binuclear nickel-NHC complexes (28-30) showed high efficiency for the coupling of unactivated aryl chlorides, leading to biaryls and terphenyls in good to excellent yields under mild conditions (Scheme 6). For all aryl chlorides, the binuclear nickel catalysts showed activities higher than those of mononuclear nickel complexes because of a possible bimetallic cooperative effect. Very recently, Zhang et al. [44] expanded this transformation using tridentate and tetradentate NHC complexes. They found that complexes 17 and 19 exhibited higher catalytic activities than those of reported Ni-NHC systems for both activated and deactivated aryl chlorides [13].
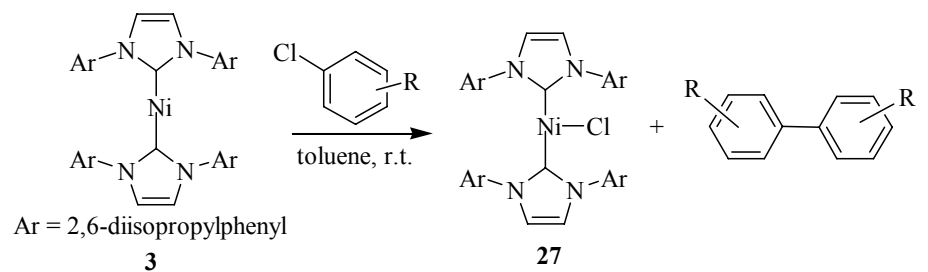

Scheme 5. Synthesis of complex 27 .

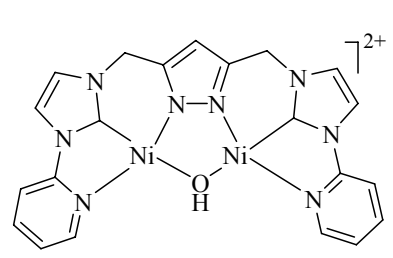

28

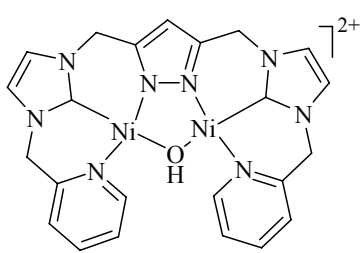

29

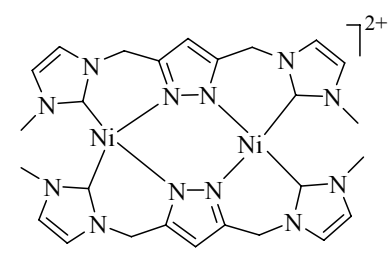

30

Scheme 6. Schematic representation of dinuclear Ni-NHC complexes. 


\subsubsection{Suzuki-Miyaura reactions}

The cross-coupling of organoboron derivatives (Suzuki-Miyaura reaction) is currently the most widely used cross-coupling protocol because many organoboron reagents are commercially available and are stable in air and moisture. The reaction can tolerate a wide range of functional groups. High activity in the coupling of aryl iodides and bromides as well as activated aryl chlorides with simple arylboronic acids have been recorded for a number of Pd-NHC catalysts. The first use of a Ni carbene complex in the Suzuki-Miyaura reaction was reported in 1999 by McGuinness et al. [2] The activity of [ $\mathrm{NiBr}(\text { tmiy })_{2}(o$-tolyl)] (tmiy=1,3,4,5-tetramethylimidazol- 2-ylidene) is limited to reactive aryl bromides. Later, Lee et al. $[4,6]$ expanded the reaction using Ni-NHC complexes. A series of Ni-NHC complexes $\left[\mathrm{Ni}(\mathrm{L})_{2}\right] \mathrm{Cl}_{2}$ (31a-31d), $\mathrm{L}=$ (1-alkyl-(3-diphenylphosphanylethyl)imidazol-2-ylidene were examined (Scheme 7) [4]. Unlike palladium which forms $\left[\mathrm{PdCl}_{2}(\mathrm{~L})\right]$ [50], the stable nickel product isolated was the ionic $\left[\mathrm{Ni}(\mathrm{L})_{2}\right] \mathrm{Cl}_{2}$. The activities of $\left[\mathrm{Ni}(\mathrm{L})_{2}\right] \mathrm{Cl}_{2}$ complexes were superior to those of other reported nickel NHC complexes $[2,6]$. In addition, 31a-31d effectively catalyzed cross-coupling between phenylboronic acid and a range of aryl halides without the need of additional $\mathrm{PPh}_{3}$. This suggested that the $\mathrm{PPh}_{2}$ functionality of the hybrid $\mathrm{NHC}$ ligand can partially replace the role of free $\mathrm{PPh}_{3}$. However, the presence of $\mathrm{PPh}_{3}$ accelerated the reaction of unreactive aryl chlorides. Complex 31b showed poorer activities than 31a, 31c, and 31d, which can be ascribed to its stronger Ni-P bond compared to the other complexes [4]. The same group also studied a series of air and moisture-stable bis-bidentate nickel complex 32. These complexes together with $\mathrm{PPh}_{3}$ showed equal catalytic activity to complexes 31a-31d in the Suzuki-Miyaura coupling reaction (Scheme 7) [51].

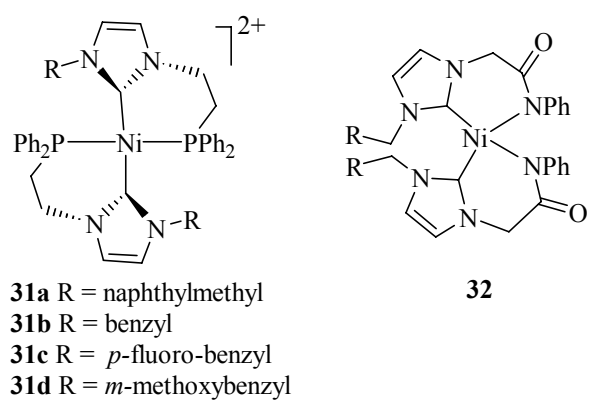

Scheme 7. P- and N-functionalised NHC complexes of nickel.

Our group has investigated the catalytic behavior of the dinuclear nickel complexes of bis(NHC) ligands (28-30) [12]. These complexes are suitable models for the study of bimetallic cooperative catalysis. As expected, these complexes were highly active for Suzuki-Miyaura and $\mathrm{Ku}$ -
mada-Corriu couplings of a range of aryl halides that include unactivated aryl chlorides using $0.2-0.8 \mathrm{~mol} \%$ catalyst. Complexes $\mathbf{2 8}$ and $\mathbf{2 9}$ showed by far the best catalytic activities yet reported in the coupling reactions of aryl chlorides with boronic acids. We believe that the high catalytic activity is due to the bimetallic cooperation of the binickel complexes.

Catalytic activities of NHC-derived nickel-pincer complexes for the Suzuki-Miyaura coupling reactions of aryl/alkenyl tosylates and mesylates have been described [52]. In the presence of $5 \mathrm{~mol} \%$ of nickelacycle 33, many tosylates and mesylates reacted with several aryl- and alkenylboronic acids to afford the coupling products in high yields (Scheme 8). More importantly, reactions employing aryl mesylates as electrophiles also were successful with 24-73\% yields using dioxane instead of 1,2-dichloethane under the optimized conditions developed for tosylates. Another group of similarly air and moisture-stable NHC-derived CNC-type pincer complexes of nickel(II) also exhibited high catalytic activity for the Suzuki-Miyaura coupling reaction of aryl bromides and chlorides with aryland alkenylboronic acids [53].

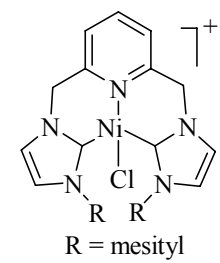

33

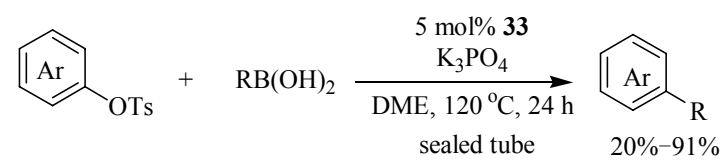

Scheme 8. Suzuki-Miyaura coupling reactions of aryl tosylates using complex 33.

\subsubsection{Heck reaction}

Since the first application of a NHC in transition metal-mediated catalysis by Herrmann et al. [54] in 1995 in the Heck reaction of bromoarenes and activated chloroarenes with $n$-butyl acrylate, a large number of Pd-NHC complexes have been investigated [55-61]. However, the Heck reaction using Ni-NHC complexes have been less studied. Ni-NHC catalysts for Heck coupling were first examined by Inamoto and co-workers in 2005 [14]. They discovered that a variety of aryl bromides and iodides can be coupled with acrylates using $5 \mathrm{~mol} \%$ of $\mathrm{Ni}(\mathrm{acac})_{2}$ and $5 \mathrm{~mol} \%$ of the appropriate $\mathrm{NHC}$ salts in the presence of $\mathrm{Na}_{2} \mathrm{CO}_{3}$ at $150{ }^{\circ} \mathrm{C}$. However, only aryl iodides and activity aryl bromides gave good yields. One year later, the authors prepared the well 
defined $\mathrm{CNC}$ pincer Ni-NHC complex 9 which was effective for the Heck coupling reaction (Scheme 9) [62]. The catalytic activity of $\mathbf{9}$ was much higher than that of $\mathrm{Ni}(\mathrm{acac})_{2} / \mathrm{NHC}$. Aryl chlorides as well as aryl iodides and bromides can be reacted when using $5 \mathrm{~mol} \%$ of 9 in the presence of $\mathrm{Na}_{2} \mathrm{CO}_{3}$ and $\mathrm{Bu}_{4} \mathrm{NI}$.

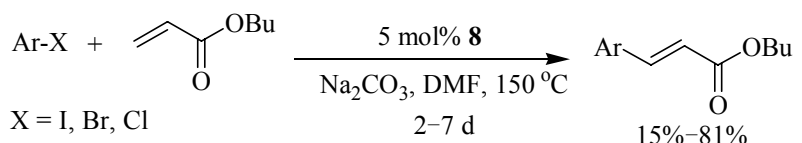

Scheme 9. Heck reaction using Ni-NHC complex 8.

\subsubsection{Nickel-NHC-catalyzed $\alpha$-arylation of acyclic ketones}

Although Kumada-Corriu coupling and Suzuki-Miyaura coupling can proceed smoothly under mild conditions with various nickel catalysts, the nickel-catalyzed $\alpha$-arylation of carbonyl compounds was not popular. The first efficient $\alpha$-arylation of acyclic ketones using complex 8a bearing both triphenylphosphine and bulky NHC ligands was described by Matsubara et al. [17] (Scheme 10). Propiophenone was arylated with several haloarenes in the presence of $\mathrm{NaO}^{t} \mathrm{Bu}$ in excellent yields, whereas the arylation of acetophenone did not occur. The coupling reactions of aryl bromides did not depend on the substituents at the para-position under these conditions. With $p$-chloroanisole, the product was obtained with a lower yield. The success of these reactions was ascribed to the bulky donating NHC ligand and the easily liberated phosphine ligand in $\mathbf{8 a}$.

\subsubsection{Others}

Other organometallic reagents such as organotitanium and organomanganese compounds have also been useful cross-coupling partners [63]. Manolikakes and co-workers [63] have developed an efficient Ni-catalyzed cross-coupling reaction of aryltitanium reagents with aryl chlorides and bromides (Scheme 11). The cross-couplings proceed at room temperature or even at lower temperatures.

Organomanganese reagents as the coupling partner can couple with various aryl halides and sulfonates [64]. It was demonstrated that $\mathrm{IPr} \cdot \mathrm{HCl}$ associated with $\mathrm{Ni}(\mathrm{acac})_{2}(3-5$ mol\%) can be used as the catalyst for the efficient coupling of functionalized aryl bromides with organomanganese reagents. Although aryl chlorides are less reactive than arylbromides, the reaction can procced at $0{ }^{\circ} \mathrm{C}$ to room temperature for both electron-deficient and electron rich aromatic bromides (Scheme 12). The new method is a valuable alternative to the Kumada-Corriu and Negishi cross-couplings.

\subsection{Carbon-heteroatom bond forming reactions}

\subsection{1 $\mathrm{C}-\mathrm{N}$ bond forming reaction}

Carbon-nitrogen bond forming reactions have been widely studied with palladium complexes bearing sterically demanding ligands such as phosphines and NHCs $[65,66]$. Much less attention has been paid to nickel-catalyzed aryl amination even though it is an attractive alternative to the more costly palladium derivatives. The first coupling of aryl chlorides with various amines was discovered using in situ generated $\mathrm{Ni}(0)$ and $\mathrm{SIPr}(\mathrm{SIPr}=1,3$-bis(2,6- diisopropylphenyl)-4,5-dihydro-1H-imidazol-3-ium) by Fort and coworkers $[15,67]$. It was revealed that active $\mathrm{Ni}(0)$ species can be generated from $\mathrm{Ni}(\mathrm{acac})_{2}$ in the presence of $\mathrm{NaH}$ and $t$-BuOH (Scheme 13). In addition, $\mathrm{NaH}$ was used to deprotonate the imidazolium salt to generate the free carbene and deprotonate the amine. Among the imidazolium salts tested,

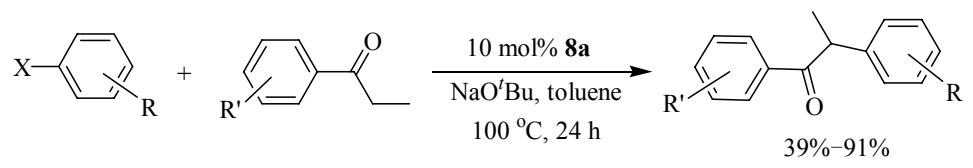

Scheme 10. $\alpha$-Arylation of acyclic ketones.

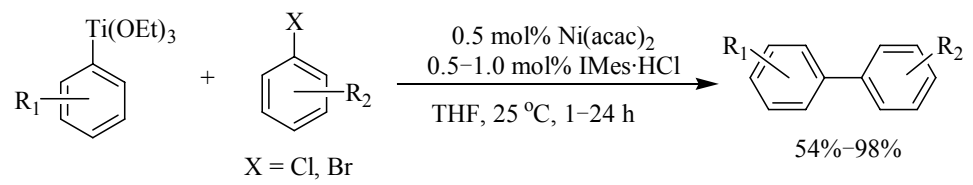

Scheme 11. Coupling reaction of aryl halides with organotitanium compounds.

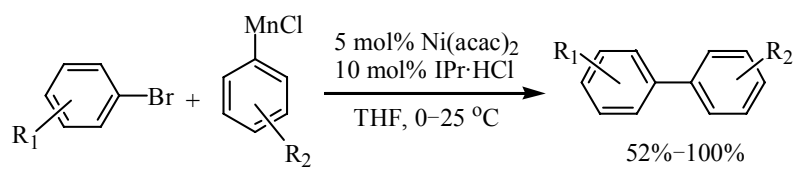

Scheme 12. Coupling reaction aryl bromides with organomanganese reagents. 


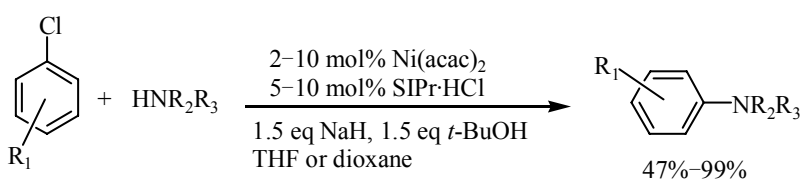

Scheme 13. Amination of aryl chlorides.

$\mathrm{SIPr} \cdot \mathrm{HCl}$ was found to be the most effective. Using this protocol, both electron-rich and electron-poor aryl chlorides were successfully coupled with secondary cyclic and acyclic amines, primary and secondary anilines, and primary alkyl amines in good yields.

In their following work, they successfully developed $N, N$-diarylation or selective $N$-monoarylation of aromatic diamines under mild conditions using the same catalyst and easily handled reagents. At the same time, they described a two-step procedure for the synthesis of unsymmetrical $N, N$-diaryl aromatic diamines [68]. As compared to several other imidazolium salts, the strongly electron donating and bulky IPr was the most effective. They also reported an alternative synthesis for nitrogen heterocycles from aryl chlorides with pendant amino groups by an intramolecular $\mathrm{Ni}(0)$-catalyzed amination reaction [69]. As seen in Scheme 14, five-, six-, and seven-membered heterocycles were formed in $73 \%-98 \%$ yields using dioxane as the solvent in the presence of $2 \mathrm{~mol} \%$ of $\mathrm{Ni}(\mathrm{acac})_{2}$ and $2 \mathrm{~mol} \%$ of SIPr $\cdot \mathrm{HCl}$. SIPr can catalyze the coupling of primary amines with aryl chlorides which bpy cannot. However, when $\mathrm{X}=$ $\mathrm{O}$, the presence of an ortho oxygen completely inhibited the Ni-SIPr-catalyzed cyclization of a seven-membered ring. The superiority of bpy relative to SIPr for the preparation of seven-membered benzoxazine rings may be due to a coordination of the SIPr-bound nickel center at the oxygen atom of the starting material.

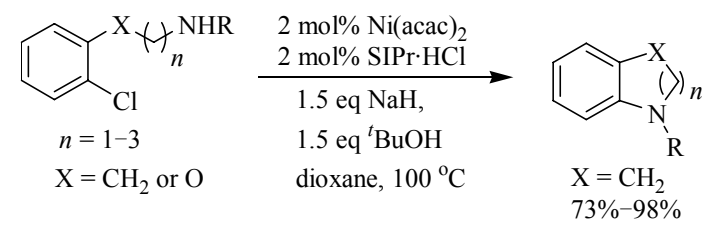

Scheme 14. Efficient intramolecular amination of aryl chlorides.

A series of Ni-NHC compounds [CpNi(NHC)]Cl 34 have also been applied to the aryl amination reactions using 5

\author{
$\sum_{\mathrm{Ni}}$ \\ $\mathrm{NHC}$ \\ 34a $\mathrm{NHC}=\operatorname{SIMes}(1,3$-dimesityl-4,5-dihydro- $1 H$-imidazol-3-ium $)$ \\ 34b $\mathrm{NHC}=\mathrm{IPr}$ \\ 34c $\mathrm{NHC}=\mathrm{SIPr}$
}

Scheme 15. Structure of $[\mathrm{CpNi}(\mathrm{NHC})] \mathrm{Cl}$ complex 34 .

mol\% of catalyst and 2 equiv of $\mathrm{KO}^{t} \mathrm{Bu}$ in dioxane at 105 ${ }^{\circ} \mathrm{C}$ (Scheme 15) [70].

In 2007, Chen et al. [71] carried out the efficient amination of aryl chlorides by Ni(II)-( $\sigma$-aryl) complex 35 and $\mathrm{IPr}$ without the need for additional reducing agents. Both electron-neutral and electron-deficient aryl chlorides were coupled smoothly using dioxane as solvent and $\mathrm{NaO}^{t} \mathrm{Bu}$ as base in the presence of $5 \quad \mathrm{~mol} \% \quad\left[\mathrm{Ni}\left(\mathrm{PPh}_{3}\right)_{2}(1-p\right.$-acetylnaphthyl)] $\mathrm{Cl}$ and $10 \mathrm{~mol} \% \mathrm{IPr} \cdot \mathrm{HCl}$ (Scheme 16). Electron-rich aryl chlorides gave good yields at elevated reaction temperature in dioxane. Under the same conditions, Gao et al. [72] explored the possibility of the amination of aryl tosylates with amines and anilines.

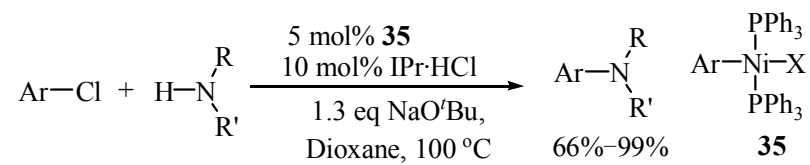

Scheme 16. Aryl amination reactions using Ni(II)-( $\sigma$-aryl) complex 35.

The zero-valent Ni-NHC complex 3 was also active for the catalytic amination of chlorobenzene with inactive anilines [73]. Higher yields of diarylamines from inactive $m$-methoxyaniline and $m$-fluoroaniline in $72 \%$ and $64 \%$ yields, respectively, was achieved. This zero-valent Ni-NHC complex can be synthesized from the reduction of $\left[\mathrm{Ni}(\mathrm{NHC})(\mathrm{acac})_{2}\right]$, and has been isolated and structurally determined (Scheme 17). This synthetic method gave a $14 \mathrm{e}$ $\mathrm{Ni}(0)$ complex in high yield and was simpler than previous methods that used air unstable $\mathrm{Ni}(\operatorname{cod})_{2}$ and $\mathrm{NHC}$ ligands.

A novel $\mathrm{C}-\mathrm{N}$ bond forming reaction using aryl methyl ethers as the electrophilic coupling partner in the presence of the $\mathrm{Ni}(\mathrm{cod})_{2}$ and a carbene ligand (Scheme 18) was reported by Tobisu et al. [74]. They developed the nickel-catalyzed amination of anisole derivatives through

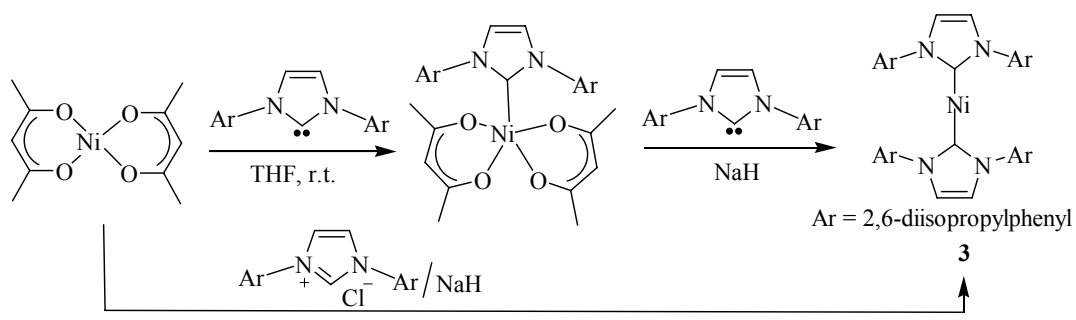

Scheme 17. Synthesis of zero-valent Ni-NHC complex 3. 


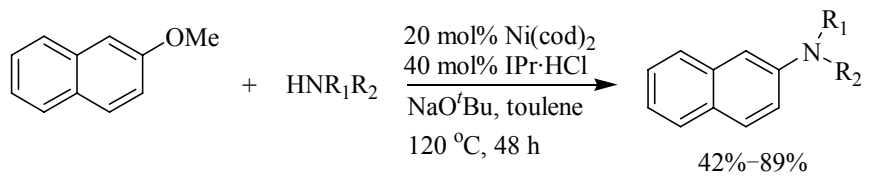

Scheme 18. C-N bond forming reaction using aryl methyl ethers as the electrophilic coupling partner.

the cleavage of carbon-oxygen bonds using toluene as solvent and $\mathrm{NaO}^{t} \mathrm{Bu}$ as the base at $120{ }^{\circ} \mathrm{C}$ in the presence of 20 $\mathrm{mol} \% \mathrm{Ni}(\mathrm{cod})_{2}$ and $40 \mathrm{~mol} \% \mathrm{IPr} \cdot \mathrm{HCl}$. Various cyclic amines and acyclic amines were successfully coupled with 2-methoxynaphthalene to produce important structural motifs commonly found in pharmaceutical substances. Due to steric hindrance, the 1-methoxyisomer resulted in a significant loss of yield. With anisole, the reaction did not proceed under these conditions. Although the reaction efficiency and substrates that can be used require further improvement, these studies clearly indicated that aryl methyl ethers can be employed as a synthetic surrogate for aryl halides in transition metal catalysis.

Very recently, Shimasaki et al. [75] demonstrated that aryl carboxylates can serve as suitable electrophilic coupling reagents in catalytic aromatic amination reactions using $\mathrm{Ni}(\mathrm{cod})_{2}$ and $\mathrm{IPr} \cdot \mathrm{HCl}$ as the catalyst. A range of monocyclic, bicyclic, and acyclic secondary amines are appropriate nucleophiles for this catalytic amination (Scheme 19). Both electron-rich and electron-deficient aryl pivalates afforded the aminated products in good yields. However, cyclohexylamine and $N$-methylaniline did not give the corresponding arylated products under the present reaction conditions, which may be due to their lower nucleophilicity.

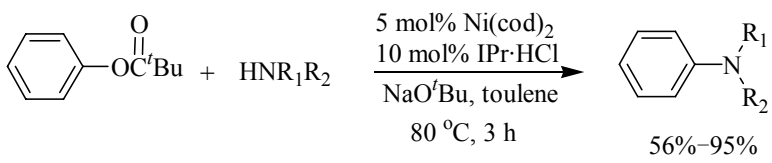

Scheme 19. Aromatic amination reactions of aryl carboxylates.

\subsection{2 $\mathrm{C}-\mathrm{S}$ bond forming reaction}

Transition metal catalyzed $\mathrm{C}-\mathrm{S}$ bond formation reactions were less explored since $\mathrm{S}$-containing species are thought to be poisonous. The only example of a NHC-based transition metal catalyst for the C-S coupling reaction was developed by Zhang et al. [76] in 2007. Ni-NHC catalysts showed good to excellent activities for various aryl halides with 1- 4 $\mathrm{mol} \% \mathrm{Ni}$ catalyst and $\mathrm{KO}^{t} \mathrm{Bu}$ as the base in DMF at $80{ }^{\circ} \mathrm{C}$ (Scheme 20). The electronic and steric characteristics of the NHC ligands greatly affect the catalytic activities.

\section{Reductive coupling reactions}

\subsection{Reductive coupling reactions in the presence of a}

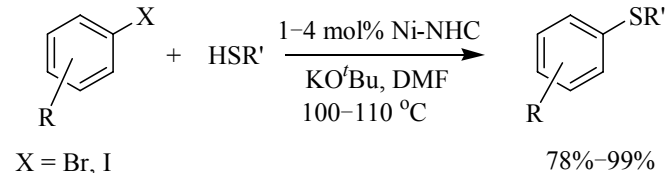

Scheme 20. C-S bond formation reaction.

reductant

\subsubsection{Ullmann-type coupling reactions using zinc as reductant}

Besides the above methods for $\mathrm{C}-\mathrm{C}$ bond formation, the Ullmann-type coupling reaction was also applied to this transformation using the Ni(II)-NHC complexes. Nickel(II) complex 36 with the bulky benzimidazolin-2-ylidene ligands was successfully applied to the Ullmann coupling reaction of aryl bromides with $1 \mathrm{~mol} \%$ catalyst loading and $65 \mathrm{~mol} \% \mathrm{Zn}$ as reducing agent (Scheme 21) [77]. Unfortunately, couplings with aryl chlorides were unsuccessful. When a N,S-heterocyclic carbene (NSHC) complex 37 was used, moderate to good yields were obtained under the standard conditions of $1 \mathrm{~mol} \%$ catalyst and $75 \mathrm{~mol} \%$ reducing zinc in an ionic liquid $\mathrm{Bu}_{4} \mathrm{NBr}$ medium [78]. Higher activities for bromoanisole and bromotoluene than bromobenzene were observed in $\mathrm{Bu}_{4} \mathrm{NBr}$.

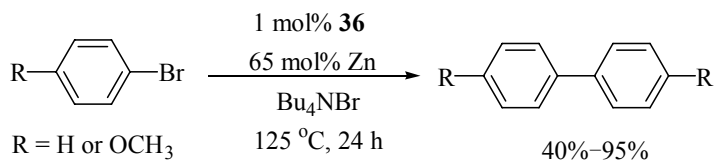

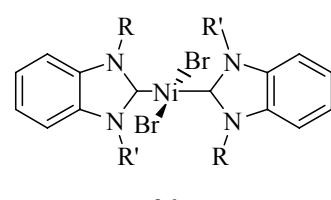

36

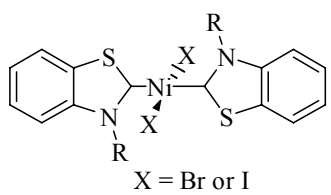

37
Scheme 21. Ullmann-type coupling reaction using complexes 36 and 37.

\subsubsection{Coupling of allenes or alkynes with aldehydes using silanes as reductant}

Since the pioneering work by Sato and co-workers [16] showed that Ni-NHC systems effectively catalyzed the coupling of 1,3-dienes and aldehydes in the presence of silanes, the reaction system has been applied in reductive coupling [79]. A silyl diene can also be used in Ni-catalyzed coupling 
reactions with aryl aldehydes (Scheme 22) [80]. An $E$ product was obtained when $\mathrm{PPh}_{3}$ was used as the ligand whereas reactions with IMes $\cdot \mathrm{HCl}$ as ligand gave $Z$ products.

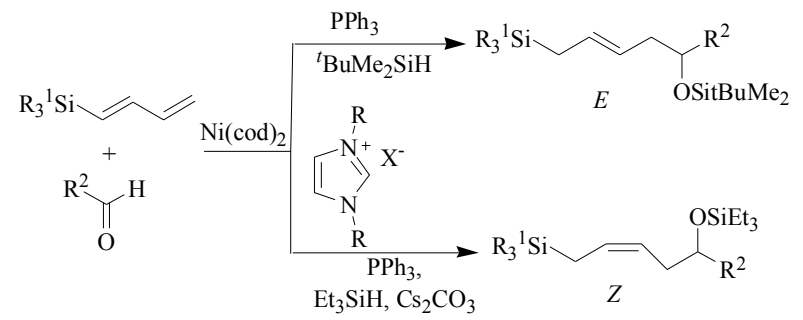

Scheme 22. Coupling reactions of diene and various aldehydes.

In 2004, Montgomery and co-workers [81,82] developed an efficient and selective reductive coupling reaction of aldehydes and alkynes using NHCs as ligands with silanes as the reductant. Good to excellent yields were obtained regardless of the aromatic and aliphatic aldehydes using the combination of $10 \mathrm{~mol} \% \mathrm{Ni}(\operatorname{cod})_{2}$ and $10 \mathrm{~mol} \% \mathrm{IMes} \cdot \mathrm{HCl}$ (Scheme 23). In addition, good regioselectivity was observed except with an internal aliphatic alkyne. Later, they applied this procedure to the macrocyclization of ynals containing terminal alkynes using a catalyst of $\mathrm{Ni}(\operatorname{cod})_{2}$, $\mathrm{KO}^{t} \mathrm{Bu}$, and $\mathrm{IMes} \cdot \mathrm{HCl}$ in toluene [82]. The procedure can also be used for the synthesis of allylic alcohols using the catalytic asymmetric coupling of aldehydes and alkynes

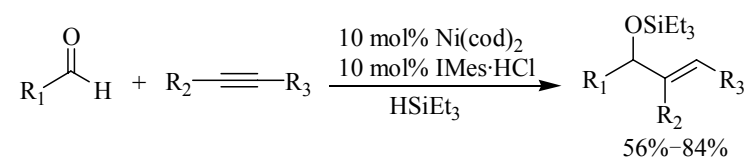

Scheme 23. Coupling reactions of alkynes and various aldehydes using $\mathrm{Ni}(\operatorname{cod})_{2}$ and IMes $\cdot \mathrm{HCl}$. using the new chiral NHC ligand $\mathbf{3 8}$ [83]. The reaction is tolerant of various functional groups including aromatic aldehydes, internal alkynes, and terminal alkynes (Scheme 24). Although prior studies had shown good to excellent enantioselectivities with specific substrate combinations, the simpler experimental protocol (fast reaction at room temperature with a stable reducing agent) provides significant preparative advantages, and the range of substrates is the broadest of any single method to date.

An asymmetric three-component coupling of 1,3-dienes, aldehydes, and silane was achieved using a Ni-NHC catalyst. Various coupling products were produced in good yields with high regio-, diastereo-, and enantioselectivities. Compared to the extensive and successful results of NHC as a ligand for transition metal-catalyzed reactions, asymmetric reactions utilizing chiral NHC ligand 39 in which a high enantioselectivity ( $>90 \%$ ee) was obtained has been rarely achieved (Scheme 25) [84]. The present results pave the way for the extension of the utilization of NHCs as chiral ligands.

A highly regioselective nickel-catalyzed reductive coupling of propargyl alcohol derivatives and aldehydes has been developed by Montgomery and co-workers (Scheme 26) [85]. They showed that the subtle electronic influences of an alkyne may be enhanced with protecting group strategies and can be matched with ligand size effects to allow excellent control of regiochemistry in aldehyde-alkyne reductive couplings. The interplay of steric and electronic considerations in nickel-catalyzed reductive coupling provides a strategy for controlling the regiochemistry of a variety of substrate combinations, including the couplings of propargyl alcohols. For a number of desirable regiochemical

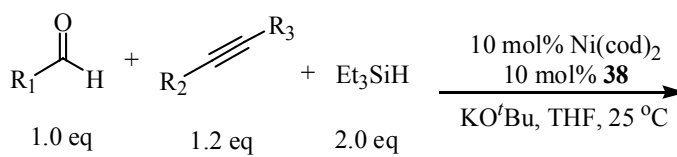
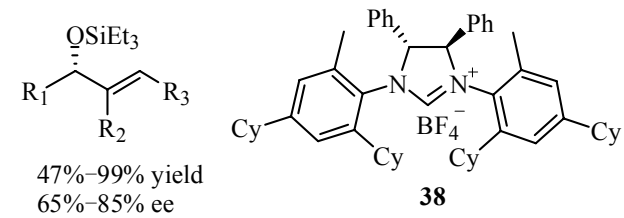

Scheme 24. Coupling reactions of alkynes and various aldehydes using $\mathrm{Ni}(\operatorname{cod})_{2}$ and ligand $\mathbf{3 8}$.
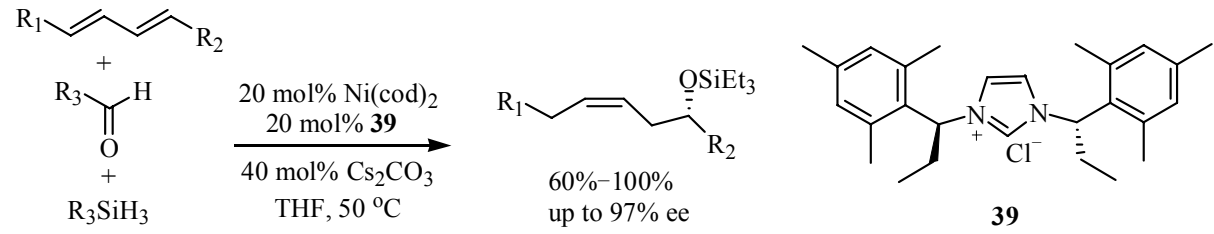

39

Scheme 25. Coupling reactions of diene and various aldehydes using $\mathrm{Ni}(\operatorname{cod})_{2}$ and ligand $\mathbf{3 9}$.

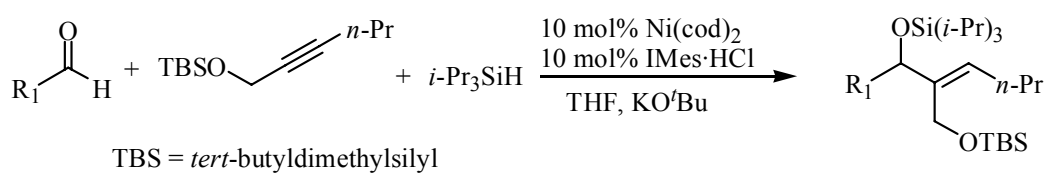

$87: 13-98: 2$ regioselectivity

Scheme 26. Highly regioselective reductive coupling reactions of propargyl alcohol derivatives and aldehydes. 


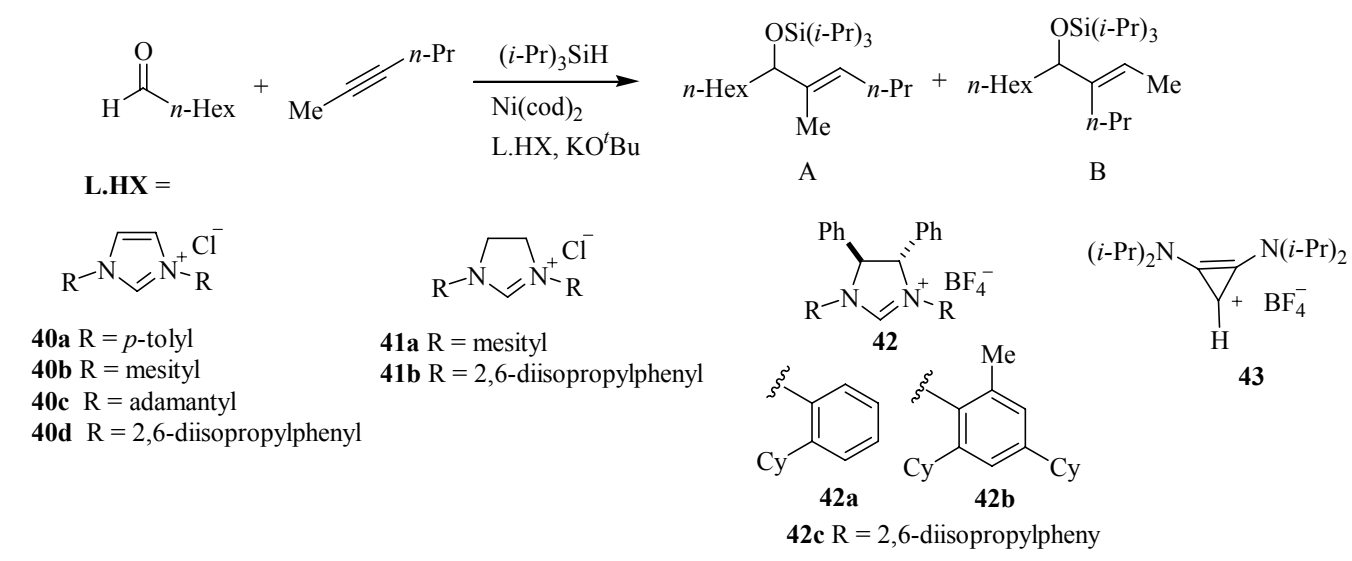

Scheme 27. Reductive couplings of heptaldehyde with 2-hexyne using various NHC ligands.

reactions that are not possible by direct coupling strategies, the derivatization of propargyl alcohol-derived products provides an indirect but effective alternative.

Very recently, Montgomery and co-workers [86] developed a general strategy for regioselectivity control in Ni-NHC-catalyzed reductive couplings of aldehydes and alkynes. They illustrated that with the careful optimization of the ligand structure, the impact of ligand size effects is substantial and can override substrate-derived influences with a broad range of both biased and unbiased alkynes (Scheme 27). As shown in Table 1, the use of cyclopropenylidene ligand $\mathbf{4 3}$ and highly hindered NHC ligands $\mathbf{4 1 b}$ and $42 \mathrm{c}$ provided a dramatic regiochemical reversal in nickel-catalyzed reductive coupling reactions of heptaldehyde with 2-hexyne.

Table 1 Ligand effects in couplings of 2-hexyne

\begin{tabular}{lc}
\hline L.HX & Regioselectivity (A:B) \\
\hline 40a & $87: 13$ \\
40b & $67: 33$ \\
40c & $44: 56$ \\
40d & $20: 80$ \\
41a & $61: 39$ \\
41b & $7: 93$ \\
42a & $75: 25$ \\
42b & $29: 71$ \\
42c & $6: 94$ \\
43 & $86: 14$ \\
\hline
\end{tabular}

\subsection{Reductive coupling reactions in the absence of a reductant}

Different from the above reductive coupling, cyclobutanones can be coupled with alkynes to afford ring-expanded cyclohexenones using Ni-NHC complexes in the absence of a reducing reagent (Scheme 28) [87]. The ligand chosen (NHC or phosphine) had an effect on the type of product. The replacement of the phosphine ligand with a NHC ligand such as IPr afforded the desired cyclohexenone product in good yields.

Analogous to the above reaction, three-component catalytic processes have been discovered by the same authors (Scheme 29) [88]. Enones, alkynes, and aldehydes can be coupled into 1,3-diketones with remarkable chemoselectivity in the absence of reducing agents due to an internal redox process. The regioselectivity and the aldehydes that can be used were influenced by the ligand used ( $\mathrm{NHC}$ or phosphine). The high chemoselectivity is unusual, particularly for aldehyde, enone, alkyne couplings that involve three different $\pi$-components.

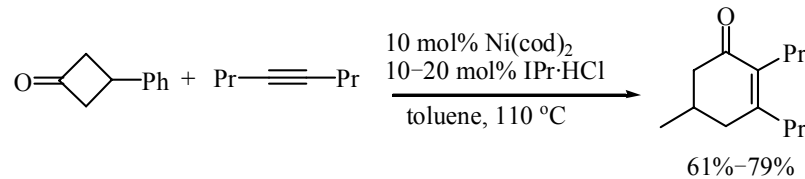

Scheme 28. Reductive coupling reaction of cyclobutanone with alkyne.
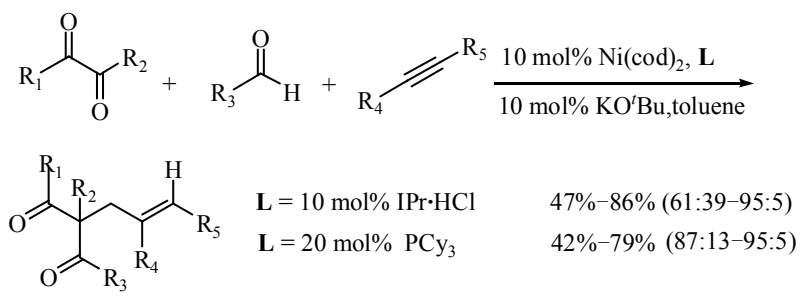

Scheme 29. Three-component catalytic processes using enones, alkynes, and aldehydes.

\section{Conclusions}

A number of nickel-catalyzed C-C and C-heteroatom formation reactions can be catalyzed with the appropriate choice of a $N$-heterocyclic carbene ligand. Both structurally well defined nickel complexes and in situ generated catalytically active species have been used. In many cases, bulky NHC ligands such as IPr, SIMes, and IMes exhibit higher efficiencies than less steric ligands due to their better 
reductive elimination in the catalytic cycles. Hemi-labile NHC ligands are a family of promising ligands since they can generate coordinatively unsaturated species that allow the complexation of substrates during the catalytic cycle, while at the same time the strong donor moiety remains connected to the metal center. For large scale industrial applications of nickel-catalyzed organic transformations, attention should be given to the economics. The development of a new generation of nickel-NHC complexes with high turnover frequencies is required. More attention should be paid to recyclable catalysts and ligands to reduce cost and pollution. Asymmetric synthesis using chiral NHC ligands is also promising due to their easy availability and low toxicity as compared to chiral phosphines. The use of NHC complexes in drugs and material synthesis is expected in the near future.

\section{References}

1 Arduengo A J, Harlow R L, Kline M. J Am Chem Soc, 1991, 113: 361

2 McGuinness D S, Cavell K J, Skelton B W, White A H. Organometallics, 1999, 18: 1596

3 Inamoto K, Kuroda J, Sakamoto T, Hiroya K. Synthesis, 2007: 2853

4 Lee C C, Ke W C, Chan K T, Lai C L, Hu C H, Lee H M. Chem Eur J, 2007, 13: 582

5 Xi Z X, Zhang X M, Chen W Z, Fu S Z, Wang D Q. Organometallics, 2007, 26: 6636

6 Chiu P L, Lai C L, Chang C F, Hu C H, Lee $\mathrm{H}$ M. Organometallics, 2005, 24: 6169

7 Wolf J, Labande A, Daran J C, Poli R. J Organomet Chem, 2006, 691: 433

8 Schneider S K, Rentzsch C F, Krueger A, Raubenheimer H G, Herrmann W A. J Mol Catal A, 2007, 265: 50

9 Xi Z X, Liu B, Chen W Z. J Org Chem, 2008, 73: 3954

10 Böhm V P W, Weskamp T, Gstottmayr C W K, Herrmann W A. Angew Chem, Int Ed, 2000, 39: 1602

11 Böhm V P W, Gstöttmayr C W K, Weskamp T, Herrmann W A. Angew Chem, Int Ed, 2001, 40: 3387

12 Zhou Y B, Xi Z X, Chen W Z, Wang D Q. Organometallics, 2008, 27: 5911

13 Xi Z X, Zhou Y B, Chen W Z. J Org Chem, 2008, 73: 8497

14 Inamoto K, Kuroda J, Danjo T, Sakamoto T. Synlett, 2005: 1624

15 Gradel B, Brenner E, Schneider R L, Fort Y. Tetrahedron Lett, 2001, 42: 5689

16 Sato Y, Sawaki R, Mori M. Organometallics, 2001, 20: 5510

17 Matsubara K, Ueno K, Koga Y, Hara K. J Org Chem, 2007, 72: 5069

18 Duong H A, Cross M J, Louie J. J Am Chem Soc, 2004, 126: 11438

19 Tekavec T N, Arif A M, Louie J. Tetrahedron, 2004, 60: 7431
20 Tekevac T N, Louie J. Org Lett, 2005, 7: 4037

21 Duong H A, Louie J. Tetrahedron, 2006, 62: 7552

22 Tekavec T N, Zuo G, Simon K, Louie J. J Org Chem, 2006, 71: 5834

23 McGuinness D S, Mueller W, Wasserscheid P, Cavell K J, Skelton B W, White A H, Englert U. Organometallics, 2002, 21: 175

24 MacKinnon A L, Baird M C. J Organomet Chem, 2003, 683 114

25 Wang X, Liu S, Jin G X. Organometallics, 2004, 23: 6002

26 Ketz B E, Ottenwaelder X G, Waymouth R M. Chem Commun, 2005: 5693

27 Li W F, Sun H M, Chen M Z, Wang Z G, Hu D M, Shen Q, Zhang Y. Organometallics, 2005, 24: 5925

28 Buchowicz W, Koziol A, Jerzykiewicz L B, Lis T, Pasynkiewicz S, Pecherzewska A, Pietrzykowski A. J Mol Catal A, 2006, 257: 118

29 Benson S, Payne B, Waymouth R M. J Polym Sci Part A: Polym Chem, 2007, 45: 3637

30 Li W F, Sun H M, Chen M Z, Shen Q, Zhang Y. J Organomet Chem, 2008, 693: 2047

31 Sujith S, Noh E K, Lee B Y, Han J W. J Organomet Chem, 2008, 693: 2171

32 Xie L Z, Sun H M, Hu D M, Liu Z H, Shen Q, Zhang Y. Polyhedron, 2009, 28: 2585

33 Buchowicz W, Wojtczak W, Pietrzykowski A, Lupa A, Jerzykiewicz L B, Makal A, Wozniak K. Eur J Inorg Chem, 2010: 648

34 Schaub T, Radius U. Chem Eur J, 2005, 11: 5024

35 Kuhl S, Schneider R, Fort Y. Organometallics, 2003, 22: 4184

36 Desmarets C, Kuhl S, Schneider R, Fort Y. Organometallics, 2002, 21: 1554

37 Diez-Gonzalez S, Marion N, Nolan S P. Chem Rev, 2009, 109: 3612

38 Tekavec T N, Louie J. Top Organomet Chem, 2007, 21:159

39 Poyatos M, Mata J A, Peris E. Chem Rev, 2009, 109: 3677

40 Kremzow D, Seidel G, Lehmann C W, Furstner A. Chem Eur $J, 2005,11: 1833$

41 Matsubara K, Ueno K, Shibata Y. Organometallics, 2006, 25 : 3422

42 Gu S J, Chen W Z. Organometallics, 2009, 28: 909

43 Liu A L, Zhang X M, Chen W Z. Organometallics, 2009, 28: 4868

44 Zhang C, Wang Z X. Organometallics, 2009, 28: 6507

45 Kim C B, Jo H, Ahn B K, Kim C K, Park K. J Org Chem, 2009, 74: 9566

46 Huynh H V, Jothibasu R. Eur J Inorg Chem, 2009: 1926

47 Berding J, Lutz M, Spek A L, Bouwman E. Organometallics, 2009, 28: 1845

48 Berding J, van Dijkman T F, Lutz M, Spek A L, Bouwman E. Dalton Trans, 2009: 6948

49 Miyazaki S, Koga Y, Matsumoto T, Matsubara K. Chem Commun, 2010, 46: 1932

50 Lee H M, Chiu P L, Zeng J Y. Inorg Chim Acta, 2004, 357: 4313 
51 Liao C Y, Chan K T, Chang Y C, Chen C Y, Tu C Y, Hu C H, Lee H M. Organometallics, 2007, 26: 5826

52 Kuroda J I, Inamoto K, Hiroya K, Doi T. Eur J Org Chem, 2009: 2251

53 Inamoto K, Kuroda J, Kwon E, Hiroya K, Doi T. J Organomet Chem, 2009, 694: 389

54 Herrmann W A, Elison M, Fischer J, Köcher C, Artus G R J. Angew Chem, Int Ed, 1995, 34: 2371

55 Zhang X M, Xi Z X, Liu A L, Chen W Z. Organometallics, 2008, 27: 4401

56 Zhang X M, Liu A L, Chen W Z. Org Lett, 2008, 10: 3849

57 Ye J S, Chen W Z, Wang D Q. Dalton Trans, 2008: 4015

58 McGuinness D S, Cavell K J. Organometallics, 2000, 19: 741

59 Grundemann S, Albrecht M, Loch J A, Faller J W, Crabtree R H. Organometallics, 2001, 20: 5485

60 Peris E, Loch J A, Mata J, Crabtree R H. Chem Commun, 2001: 201

61 Loch J A, Albrecht M, Peris E, Mata J, Faller J W, Crabtree R H. Organometallics, 2002, 21: 700

62 Inamoto K, Kuroda J, Hiroya K, Noda Y, Watanabe M, Sakamoto T. Organometallics, 2006, 25: 3095

63 Manolikakes G, Dastbaravardeh N, Knochel P. Synlett, 2007: 2077

64 Leleu A, Fort Y, Schneider R. Adv Synth Catal, 2006, 348: 1086

65 Viciu M S, Kissling R M, Stevens E D, Nolan S P. Org Lett, 2002, 4: 2229

66 Stauffer S R, Lee S, Stambuli J P, Hauck S I, Hartwig J F. Org Lett, 2000, 2: 1423

67 Desmarets C, Schneider R, Fort Y. J Org Chem, 2002, 67: 3029

68 Kuhl S, Fort Y, Schneider R. J Organomet Chem, 2005, 690: 6169
69 Omar-Amrani R, Thomas A, Brenner E, Schneider R, Fort Y. Org Lett, 2003, 5: 2311

70 Kelly R A, Scott N M, Diez-Gonzalez S, Stevens E D, Nolan S P. Organometallics, 2005, 24: 3442

71 Chen C, Yang L M. J Org Chem, 2007, 72: 6324

72 Gao C Y, Yang L M. J Org Chem, 2008, 73: 1624

73 Matsubara K, Miyazaki S, Koga Y, Nibu Y, Hashimura T, Matsumoto T. Organometallics, 2008, 27: 6020

74 Tobisu M, Shimasaki T, Chatani N. Chem Lett, 2009, 38: 710

75 Shimasaki T, Tobisu M, Chatani N. Angew Chem, Int Ed, 2010, 49: 2929

76 Zhang Y G, Ngeow K C, Ying J Y. Org Lett, 2007, 9: 3495

77 Huynh H V, Wong L R, Ng P S. Organometallics, 2008, 27: 2231

78 Ding N, Zhang J, Hor T S A. Dalton Trans, 2009: 1853

79 Ng S-S, Jamison T F. J Am Chem Soc, 2005, 127: 7320

80 Sawaki R, Sato Y, Mori M. Org Lett, 2004, 6: 1131

81 Mahandru G M, Liu G, Montgomery J. J Am Chem Soc, 2004, 126: 3698

82 Knapp-Reed B, Mahandru G M, Montgomery J. J Am Chem Soc, 2005, 127: 13156

83 Chaulagain M R, Sormunen G J, Montgomery J. J Am Chem Soc, 2007, 129: 9568

84 Sato Y, Hinata Y, Seki R, Oonishi Y, Saito N. Org Lett, 2007, 9: 5597

85 Malik H A, Chaulagain M R, Montgomery J. Org Lett, 2009, 11: 5734

86 Malik H A, Sormunen G J, Montgomery J. J Am Chem Soc, 2010, 132: 6304

87 Murakami M, Ashida S, Matsuda T. J Am Chem Soc, 2005, 127: 6932

88 Herath A, Li W, Montgomery J. J Am Chem Soc, 2007, 130: 469 